\title{
Analyzing Thermal Module Developments and Trends in High-Power LED
}

\author{
Jung-Chang Wang \\ Department of Marine Engineering, National Taiwan Ocean University (NTOU), No. 2 Pei-Ning Road, Keelung 20224, Taiwan \\ Correspondence should be addressed to Jung-Chang Wang; jcwang@ntou.edu.tw
}

Received 27 February 2014; Revised 8 April 2014; Accepted 11 April 2014; Published 18 May 2014

Academic Editor: Ching-Song Jwo

Copyright (C) 2014 Jung-Chang Wang. This is an open access article distributed under the Creative Commons Attribution License, which permits unrestricted use, distribution, and reproduction in any medium, provided the original work is properly cited.

\begin{abstract}
The solid-state light emitting diode (SSLED) has been verified as consumer-electronic products and attracts attention to indoor and outdoor lighting lamp, which has a great benefit in saving energy and environmental protection. However, LED junction temperature will influence the luminous efficiency, spectral color, life cycle, and stability. This study utilizes thermal performance experiments with the illumination-analysis method and window program (vapour chamber thermal module, VCTM V1.0) to investigate and analyze the high-power LED (Hi-LED) lighting thermal module, in order to achieve the best solution of the fin parameters under the natural convection. The computing core of the VCTM program employs the theoretical thermal resistance analytical approach with iterative convergence stated in this study to obtain a numerical solution. Results showed that the best geometry of thermal module is $4.4 \mathrm{~mm}$ fin thickness, $9.4 \mathrm{~mm}$ fin pitch, and $37 \mathrm{~mm}$ fin height with the LED junction temperature of $58.8^{\circ} \mathrm{C}$. And the experimental thermal resistances are in good agreement with the theoretical thermal resistances; calculating error between measured data and simulation results is no more than $\pm 7 \%$. Thus, the Hi-LED illumination lamp has high life cycle and reliability.
\end{abstract}

\section{Introduction}

High-power light-emitting diodes (Hi-LEDs) of the solidstate semiconductor devices are emerging and growing rapidly in the globe nowadays. They are employed by indoor and outdoor lighting lamps with white Hi-LEDs appearance, which has many particular advantages involving small size, light weight, long lifetime, quick time response, antivibration, low power consumption, and energy saving issues [1]. Although Hi-LED lighting lamps with less carbon emission are renewable and clean for our living environment and their response time is very short resulting from solid-state direct driving of low voltage, the thermal management and control (TM\&C) is needed urgently to resolve the problems of luminous efficiency $(\mathrm{lm} / \mathrm{W})$ and light costs $(\mathrm{NTD} / \mathrm{lm})$ for Hi-LEDs lighting lamps. Single Hi-LED with $1 \mathrm{~mm}^{2}$ area usually has above $100 \mathrm{~W} / \mathrm{cm}^{2}$ heat flux. This serious thermal concentration results in a hot-spot phenomenon, and how to control thermal energy is still a major issue to deal with during device packing and application of Hi-LEDs [2-4]. The heat dissipation problems of Hi-LED include three parts including chip heat dissipation, encapsulation, and system level. LEDs are mounted on metal printed circuit board (MPCB) to enable good dissipation of heat generated from the LEDs. Currently, LED based plates may be divided into several kinds [5-8]. Their responsibility is to conduct heat capacity to the exterior surroundings through the thermal module. The junction temperature $\left(T_{j}\right)$ of LED immediately influences luminous efficiency and quality. This is because the light intensity of LEDs and lifetime of the P-N composition plane $T_{j}$ change in inverse proportion, so it is an important thermal management problem to reduce the $T_{j}$ surpassing $60^{\circ} \mathrm{C}$ [9]. Higher junction temperature reduces the luminous flux output and brightness and also affects the wave length of photons, changing LED illumination color and lowering its lifetime. It quickly transfers the heat generated by the LED chip to an external heat sink, and through the based plate and cooling module to dissipate heat to the surroundings, can increase the intensity of illumination and LED lifetime.

Eisermann et al. [10] used insulating high-intensity lightemitting diodes aluminum substrates to be attached to a conductor deposited on the dielectric with low-cost systems. 


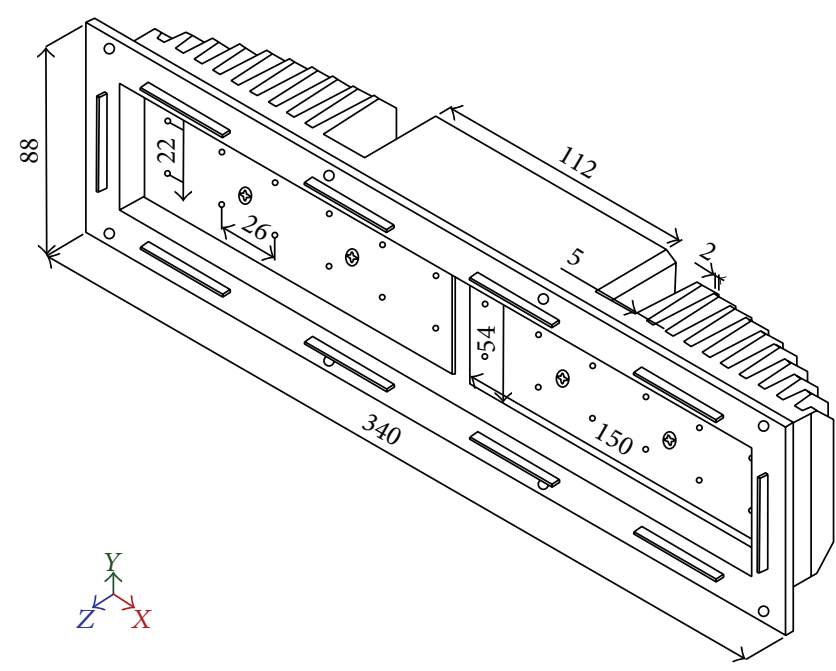

FIgURE 1: LED illumination lamp.

Arik et al. [11, 12] pointed that the heat flux raises over $80 \mathrm{~W} / \mathrm{cm}^{2}$ with the steady increase in LED power consumption resulting in a hot-spot phenomenon problem. In addition, the high spreading resistance is caused by the heat sink, which has a larger area than the chip. The hot-spot effect and high spreading resistance result in a higher junction temperature for the LED, which should be kept under $120^{\circ} \mathrm{C}$. The reliability and lighting life of LEDs are dependent on junction temperature in normal operating temperature. Wang et al. [13] applied a vapor chamber in a 30 Watt high-power LEDs vapor chamber-based plate and utilized the Windows program VCTM V1.0 to calculate the thermal performance of a LEDs vapor chamber-based plate thermal module. Because of the high thermal performance of the vapour chamber (thermal conductivity above $800 \mathrm{~W} / \mathrm{mK}$ ), which solves the hot-spot problem of Hi-LEDs, the proposal method can spread the heat of the LEDs rapidly to the vapour chamber and conduct it to the thermal module [14-16].

The LED illumination lamp configuration utilized in this paper is shown in Figure 1. There are twelve LED chips (2 $\times 6$ matrixes) of white color on single aluminum metal core printed circuit board (Al-MCPCB). The dimensions of single LED chip and Al-MCPCB are $1 \times 1 \mathrm{~mm}^{2}$ and $150 \times$ $54 \times 2 \mathrm{~mm}^{3}$, respectively. One LED lighting module has two Al-MCPCBs with twenty-four LED chips. The overall dimensions and material of the present heat sink are $340 \times 88 \times$ $50 \mathrm{~mm}^{3}$ and die-casting aluminum. There are twenty taper fins $\left(2 \times 5 \mathrm{~mm}^{2}\right)$ to dissipate heat capacity from Hi-LEDs into surroundings. Ten fins heights are 12, 18, 22, 26, 30, 32, 34, 35,36 , and $37 \mathrm{~mm}$ successively and place center symmetry with pitch of $9 \mathrm{~mm}$. And the weight of the whole heat sink is about $1.92 \mathrm{~kg}$. The paper utilized the thermal performance illumination experiments and numerical analysis to test and design the thermal module of LED lighting lamp, especially, in order to obtain these better parameters including lower LED junction temperature, fin geometries, lighter weight of heat sink, and LED vapour chamber-based plate through thermal resistance analysis and VCTM V1.0 [13].

\section{Analysis Methodology}

2.1. Thermal Performance Experiment and Procedure. Figure 2 reveals the experimental apparatus and thermal resistance network of one Hi-LED lighting module. The experimental methods stated in this paper are mainly aimed at testing the thermal performance of the one LED lighting module supplied by Macroblock Corp. in Taiwan. Digital power supply of ADC50-10 with a maximum voltage and ample of 50 and 10 , respectively, is directly connected to Hi-LEDs heat source and supplies the direct current (D.C.) for four kinds of input powers involving 16, 20,24, and $30 \mathrm{~W}$. Another input power is alternative current (A.C.) with 110 volts to the one Hi-LED lighting module. The measurement error of the digital power supply is $\pm(0.5 \%+2$ digits $)$. All measured temperature points are sixteen T-type thermocouples composed of the materials of copper and nickel as shown in Figure 3. A thermocouple named $\mathrm{CH} 14$ is attached on the surface of the LED chip to measure the maximum temperature $\left(T_{L}\right)$. $\mathrm{CH} 15$ measures the side temperature $\left(T_{S}\right)$ near the LED chip. Four thermocouples $(\mathrm{CH} 1$ to $\mathrm{CH} 4)$ are attached on the front surface of Al-MCPCB to measure its temperature. And $T_{M}$ is the mean temperature of them. $T_{F}$ is the average temperature of $\mathrm{CH} 5$ to $\mathrm{CH} 8$ that are measuring the skin temperatures of fins. $\mathrm{CH} 9$ measures the temperature of power adapter belonging to Hi-LED light module. $\mathrm{CH} 10$ to $\mathrm{CH} 13$ are the reference temperatures in order to compare numerical temperatures. Lastly, a thermocouple is placed on the back side of the Hi-LED lighting module to measure the ambient temperature $\left(T_{a}\right)$. These thermocouples are connected to the data recorder of GL800APS, which has 40 measuring channels and the recording time is $0.1 \mathrm{~ms}$, to record their values, and the measurement error is $\pm 1 \%$. Thermocouple of type $T$ has a maximum measuring range from $-200^{\circ} \mathrm{C}$ to $+350^{\circ} \mathrm{C}$ and an error range of $\pm 0.5^{\circ} \mathrm{C}$. When the temperatures and illumination of LED are in a steady state and their recording curves appear as a horizontal line, one experimental team stops. Every team spends about one hour. There are three inclined angles of $0^{\circ}$ (horizontality), $-90^{\circ}$ (verticality), and $90^{\circ}$ (antigravity) to experiment as shown in Figure 4 in the present study.

Equation (1) defined the thermal resistances, which are generally employed to assess the thermal performances of a thermal module and also an important parameter in thermal module design. The larger the total thermal resistance is, the poorer the thermal performance of thermal modules is and the higher the junction temperature of Hi-LEDs heat source is. Consider

$$
R_{t}=\frac{\Delta T}{Q_{\text {in }}}=R_{L}+R_{M}+R_{\mathrm{HS}}+R_{a} .
$$

In (1), $R_{t}$ is the total thermal resistance $\left({ }^{\circ} \mathrm{C} / \mathrm{W}\right), \Delta T$ is the temperature difference $\left({ }^{\circ} \mathrm{C}\right)$, and $Q_{\text {in }}$ is the input power of Hi-LEDs (W). And $R_{t}$ is defined as the temperature difference (the junction temperature of LED $T_{L}$ minus the ambient temperature $T_{a}$ ) divided by the total heat transfer rate $Q_{\text {in }}$. The $R_{L}$ is the LED thermal resistance, defined as the effective temperature difference at the LED $\left(T_{L}\right.$ minus the side temperature near the LED chip $T_{S}$ ) divided by $Q_{\text {in }}$. The $R_{M}$ is the Al-MCPCB thermal resistance, defined as 


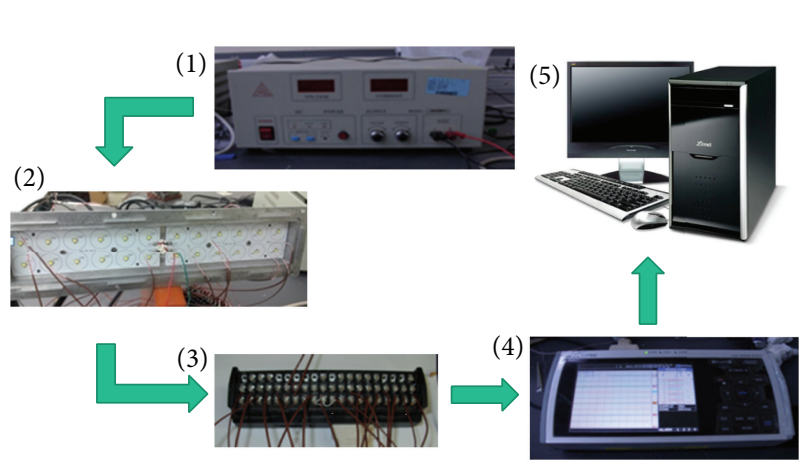

(a) Apparatus

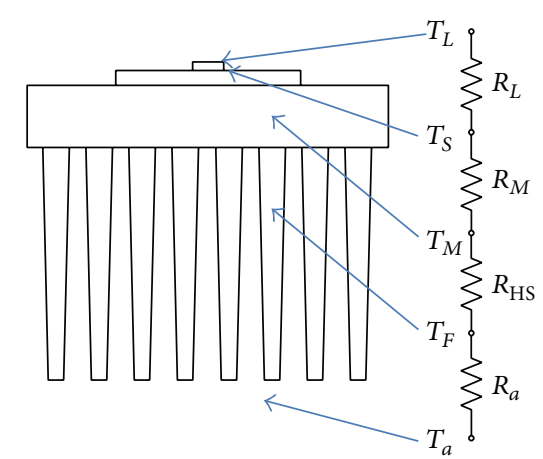

(b) Network

FIGURE 2: Experimental apparatus and thermal resistance network.

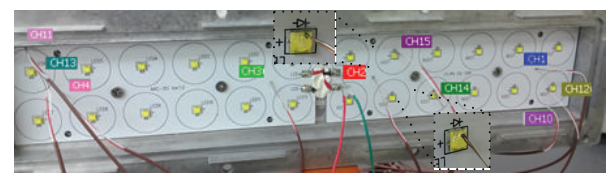

(a) Front

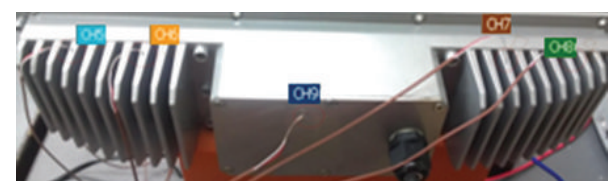

(b) Back

FIgURE 3: Measuring positions.

the temperature difference ( $T_{S}$ minus the average temperature of the Al-MCPCB $T_{M}$ ) divided by $Q_{\text {in }}$. The $R_{\mathrm{HS}}$ is the heat sink thermal resistance, defined as the temperature difference $\left(T_{M}\right.$ minus the average temperature of the fins $T_{F}$ ) divided by $Q_{\text {in }}$. The $R_{a}$ is the convection resistance, defined as the temperature difference $\left(T_{F}\right.$ minus $\left.T_{a}\right)$ divided by $Q_{\text {in }}$. Moreover, the thermal resistances belong to derived variable and include temperature and heat transfer rate, which are measured with experimental instruments. Certain error should exist between the data measured during experiment. The concept of propagation of error is introduced to calculate experimental error and fundamental functional relations for propagation of error [13]. An experimental error is represented with a relative error and the maximum relative error of thermal resistances defined is within $\pm 10 \%$ except the $R_{\mathrm{HS}}$.

2.2. Numerical Analysis. One of the major purposes of this study is to design the best thermal performance of thermal module of Hi-LED illumination lamp. Nowadays, in the LED lighting industry, conventional thermal modules of Hi-LED lamp are designed and adjusted by the engineers' experience. Consequently, manufacturing more experimental testing activities may ameliorate the thermal performance of Hi-LED lighting thermal module. However, expenses of testing samples once more and waiting time for samples preparation do not achieve the cost-efficiency for the rapid development-period market of LED lighting industry. In view of this point, employing numerical analysis is a theme in the present study. The temperature and flow fields of LED lighting model can be simulated and predicted via finite volume method (FVM) based on a 3D numerical approach belonging to computational fluid dynamics (CFD), in which fluid mechanics, discrete mathematics, numerical methods, and computer technologies are integrated by computer-aided design (CAD) and engineering (CAE). Icepak commercial electronic heat transfer analysis software developed by American Fluent Inc. is adopted in this paper. The entire analytical model can be set up and simulated through the file conversion skill between CAD/CFD. The numerical analysis can be divided into three parts involving preprocessing, numerical solving, and postprocessing. With respect to preprocessing, above all, a 3-dimensional (3D) geometrical model of LED light module is drawn and established through 3D CAD software. Moreover, some slight influence characteristics will be neglected so as to decrease the computation grid elements and simulation time when establishing $3 \mathrm{D}$ geometrical model. Although we comprehend the mechanism of free convection well, the complexities of fluid motion make it very difficult to acquire simple analytical relations for heat transfer through solving the governing equations of motion and energy. Another reason is that the natural convection heat transfer coefficient depends on the geometry of the surface as well as its orientation, variation of temperature on the surface, and the thermophysical properties of the fluid. Figure 5 exhibits the grid elements and boundary conditions. The top, bottom, and sides of the computer system cabinet are specified as open boundary conditions and the wall thickness of the enclosure is considered to be negligible.

The differential governing equation of a steady state thermal analysis of LED lighting module is shown as (2). More detailed derivations of the heat conduction equation can be found in [17]. Consider

$$
\nabla \cdot(k \nabla \cdot T)=q_{\text {in }}
$$

where $k$ is the thermal conductivity of three-dimensional model of the LED lighting system and $q_{\text {in }}$ is the LEDs input heat flux. The governing equations are solved by means of 


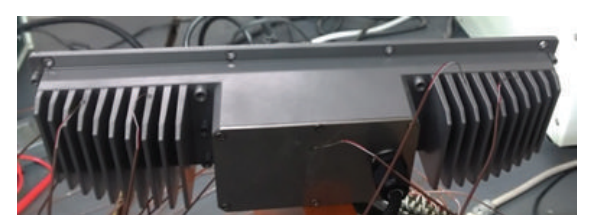

(a) $0^{\circ}$ (horizontality)

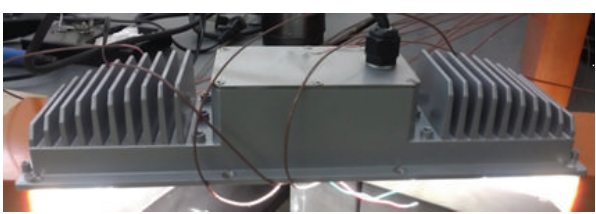

(b) $-90^{\circ}$ (verticality)

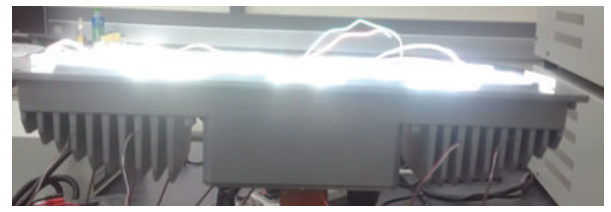

(c) $90^{\circ}$ (antigravity)

FIGURE 4: Three inclined angles.

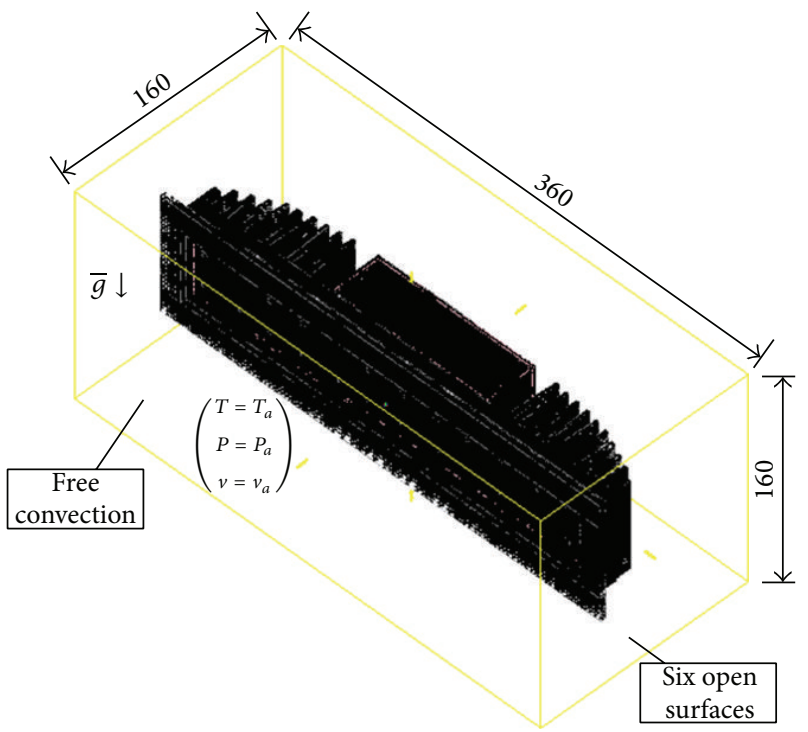

Figure 5: Mesh and boundary conditions.

the commercial software ANSYS Icepak v13.0.1 in which a finite volume scheme is used to discretize the governing equations. In conducting solid regions of LEDs lighting module, ANSYS Icepak solves a simple conduction equation that includes the heat flux due to conduction and volumetric heat sources within the solid as shown in (3). Equation (3) is solved simultaneously with the energy transport equation. Consider

$$
\frac{\partial(\rho h)}{\partial t}=\nabla \cdot(k \nabla \cdot T)+S_{h}
$$

where $\rho$ is density, $h$ is sensible enthalpy $h\left(h=\int_{T_{\text {ref }}}^{T} C_{p} d T\right.$, where $T_{\text {ref }}$ is $\left.298.15 \mathrm{~K}\right), k$ is conductivity, $T$ is temperature, and $S_{h}$ is the volumetric heat source.

In the flow regions to yield a fully coupled conduction/convection heat transfer prediction can be written through

$$
\frac{\partial(\rho h)}{\partial t}+\nabla \cdot(\rho h \bar{v})=\nabla \cdot\left(\left(k+k_{t}\right) \nabla \cdot T\right)+S_{h},
$$

where $\bar{v}$ is fluid velocity, $k_{t}$ is the conductivity due to turbulent transport $\left(k_{t}=0\right.$ in this problem), and the source term $S_{h}$ includes any volumetric heat sources you have defined. The mass and momentum conservation equations can be written, respectively, as

$$
\begin{gathered}
\frac{\partial \rho}{\partial t}+\nabla \cdot(\rho \cdot \bar{v})=0 \\
\frac{\partial(\rho \cdot \bar{v})}{\partial t}+(\rho \bar{v} \bar{v})=-\nabla p+\nabla \cdot(\overline{\bar{\tau}})+\rho \vec{g}+\vec{F},
\end{gathered}
$$

where $p$ is the static pressure, $\overline{\bar{\tau}}$ is the stress tensor $(=\mu[(\nabla \bar{v}+$ $\left.\left.\nabla \bar{v}^{T}\right)-2 / 3 \nabla \cdot \bar{v} I\right], \mu$ is the molecular viscosity, $I$ is the unit tensor, and the second term on the right-hand side is the effect of volume dilation.), $\rho \vec{g}$ is the gravitational body force, and $\vec{F}$ contains other source terms that may arise from resistances, sources, and so forth. The abovementioned governing equations are solved by Icepak code which is a commercial software program of fully $3 \mathrm{D}$ steady/unsteady and turbulent/laminar flows application in electronic heat transfer industry [17]. The finite volume method is applied to transfer the partial differential equations to algebraic relations. Then the implicit algorithm is used to solve the obtained algebraic equations. In order to solve the NavierStoks and continuity equations the SIMPLE method supplying the pressure-velocity coupling is used.

In the simulation system, two base plates are employed to evaluate the thermal performance of the Hi-LED lighting module. One is the original base plate of Al-MCPCB, and the other is the LED vapour chamber-based plate [13]. A vapor chamber made of C1100 oxygen-free copper is applied in the present paper. Its porosity of the capillary structure in the interior of cavity is under 0.5 , and the maximum fill-up amount is under $15 \mathrm{~mm}^{3}$. Pure water containing low oxygen content less than $10 \mathrm{ppb}$ is enclosed as the working fluid and filled up in the interior of the vapour chamber. Its advantages are embodied in its thermal-physics properties such as extremely high latent heat and thermal conductivity and low viscosity, as well as its nontoxicity and incombustibility. The relational theorem and thermal performance of vapour chamber based on the systematic dimensional analysis of 


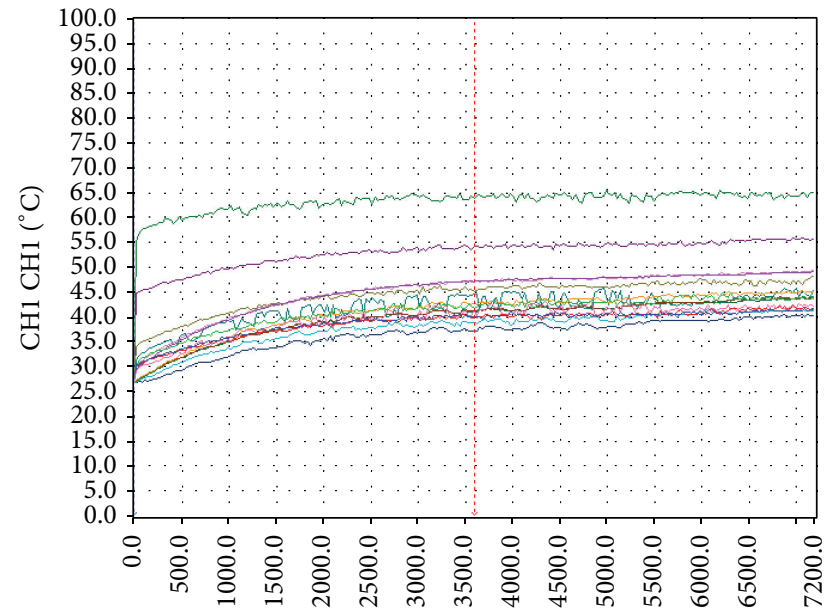

(s)

(a) D.C. $30 \mathrm{~W}$

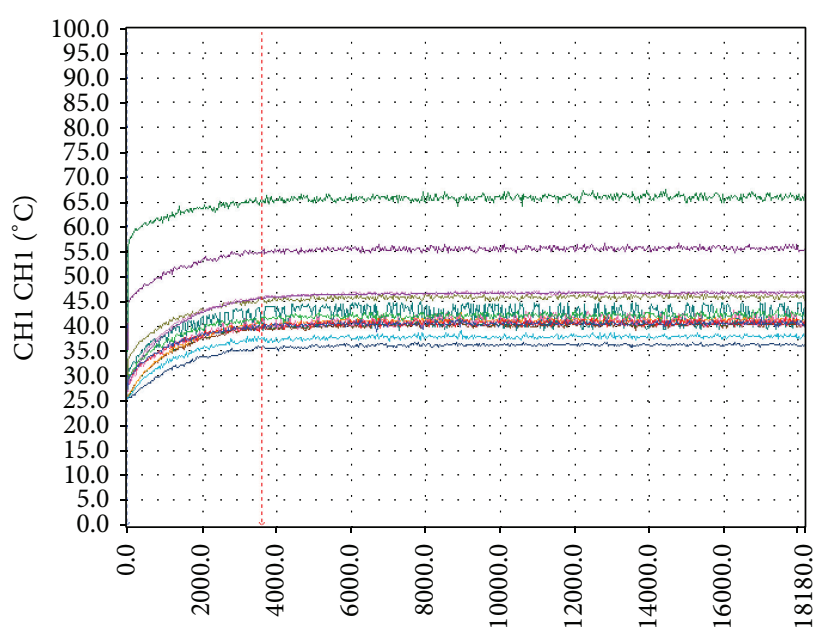

(s)

(b) A.C. $110 \mathrm{~V}$

FIgURE 6: Temperatures with time.

the [F.L.T.Ө.] in Buckingham $\Pi$ Theorem derive empirical formula of the effective thermal conductivity as $[13,18]$. In order to avoid repetition, they are not shown in this study. According to Wang's empirical equation (7), in [18], the equivalent thermal conductivity of the vapor chamber depends on its dimensions and heat flux. $L_{V . C .}$ is the length of the vapor chamber, $W_{\mathrm{V} . c .}$ is width, $t_{\mathrm{V} . \mathrm{C} .}$ is thickness, and $q_{\text {in }}$ is the heat flux of LED heat source. Consider

$$
K_{\mathrm{eff}}=46.1 \cdot\left(L_{\mathrm{V} . \mathrm{C} .} \cdot W_{\mathrm{V} . \mathrm{C}}\right)^{0.5} \cdot\left(t_{\mathrm{V} . \mathrm{C} .}\right)^{0.24} \cdot\left(q_{\mathrm{in}}\right)^{0.28} .
$$

Finally, input the boundary conditions and thermophysical properties, in which the ambient temperature $T_{a}$ is set to $25^{\circ} \mathrm{C}$ (changed with experimental surroundings); a constant external static pressure boundary condition is applied for the six open surfaces, free convection, the grid pattern is structural one and the entire simulation analysis type is steady state, and ANSYS Icepak solves the Navier-Stokes equations for transport of mass, momentum, and energy when it calculates laminar flow with heat transfer. The thermal conductivity of Al-MCPCB assumes $24 \mathrm{~W} / \mathrm{mk}$ [5]. All conditions of the simulation LED lighting models containing LED heater, heat sink, fins, and hosing are the same except the base plates. In order to validate the reliability and accuracy of the present experimental results, the boundary conditions, properties of material, and input parameters are all tallied with these experimental conditions. For the entire Hi-LED lighting module, about $2.9 \times 10^{5}$ grid elements are used, iterations are about 500, and it will take about 20 hours to simulate each scenario using one CPU calculation. Then, the problems are solved after the solution convergence with the minimum reduction in normalized residuals for each variable including continuity, momentum, and energy at less than criterions of $1.0 \times 10^{-3}$ for each case. A mesh sensitivity study is performed by changing the number of grid cells to validate the accuracy of the numerical simulations. When the total number of grid points used for the computations increases from $2.9 \times 10^{5}$ to $5.2 \times 10^{5}$, the change of the maximum CPU temperature is within $1 \%$. There is little to be gained by increasing the mesh number as this will require more computation resources and time. Therefore the grid $2.9 \times$ $10^{5}$ is sufficient for the present simulation. The comparisons of these temperatures and thermal resistances between the experimental results and the computational results of Icepak will be made. Furthermore, obtaining the velocity distributions, temperatures from the simulation results and the simulation thermal resistances are calculated through (1). The present analysis is possible to reduce much cost of manufacture and rapid design Hi-LED lighting thermal modules or improve the thermal performance of existing LED lighting system within a short period.

\section{Results and Discussions}

Figure 6 reveals the experimental results of D.C. $30 \mathrm{~W}$ and A.C. $110 \mathrm{~V}$ (A.C. $30 \mathrm{~W}$ ) at incline angle of $0^{\circ}$. All temperatures are almost stable after one hour. The $T_{L}$ of $\mathrm{CH} 14$ are about $65^{\circ} \mathrm{C}$ and $66^{\circ} \mathrm{C}$, respectively, for D.C. $30 \mathrm{~W}$ and A.C. $110 \mathrm{~V}$. Figure 7 shows the numerical results of temperature and velocity under input power of A.C. $30 \mathrm{~W}$ at incline angle of $0^{\circ}$. The maximum temperature is $62.6^{\circ} \mathrm{C}$ and velocity is $0.26 \mathrm{~m} / \mathrm{s}$. In the presence of a temperature gradient, forced convection heat transfer will occur. However, we consider situations for which there is no forced velocity by a fan or a pump in the present study, yet convection currents exist within fluid, which are referred to as nature or free convection. The free convection flow velocities are generally much smaller than those associated with forced convection. And the free convection fluid motion is due to buoyancy forces resulting from gravitational field and temperature gradient within fluid. The Grashof number (Gr) plays the same role in free convection that the Reynolds number (Re) plays in forced convection. For a vertical flat plate situation, the turbulent 


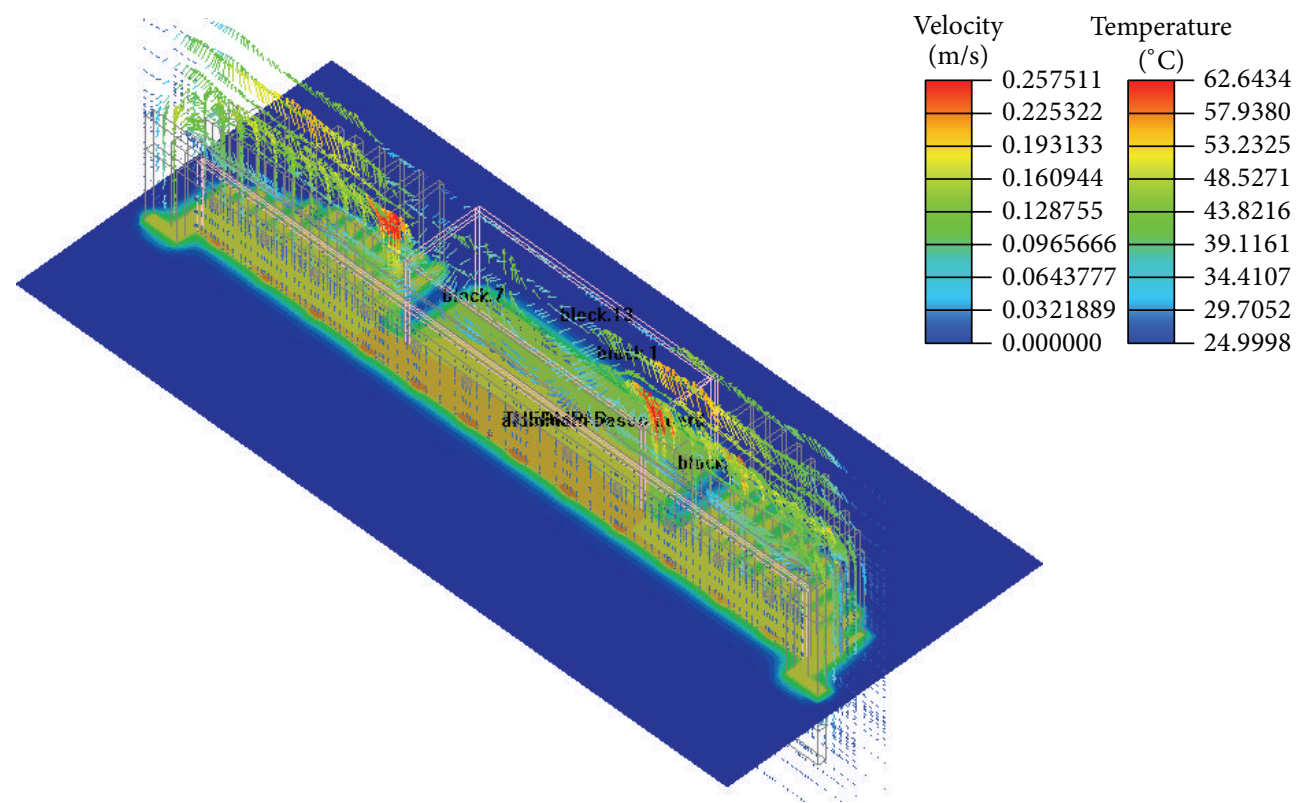

FiguRE 7: Icepak simulation results.

TABLE 1: Comparisons between experimental and numerical temperatures of D.C. $30 \mathrm{~W}\left(T_{a}=25.7^{\circ} \mathrm{C}\right)$.

\begin{tabular}{|c|c|c|c|c|c|c|c|c|c|c|c|c|c|c|c|}
\hline $\mathrm{CH}$ & 1 & 2 & 3 & 4 & 5 & 6 & 7 & 8 & 9 & 10 & 11 & 12 & 13 & 14 & 15 \\
\hline $\begin{array}{l}\text { Measured data } \\
\left({ }^{\circ} \mathrm{C}\right)\end{array}$ & 40 & 39.5 & 41.9 & 41.8 & 39.2 & 40.3 & 39.8 & 39.9 & 35.9 & 45.6 & 45.5 & 45.5 & 45.4 & 64.7 & 54.8 \\
\hline $\begin{array}{l}\text { Simulation result } \\
\left({ }^{\circ} \mathrm{C}\right)\end{array}$ & 39 & 41.1 & 41.1 & 41.8 & 39.9 & 39.2 & 40.5 & 40.5 & 41.1 & $\mathrm{X}$ & $X$ & 44.8 & 46.4 & 65.2 & 56.3 \\
\hline Error $(\%)$ & -2.5 & 4 & -1.9 & 0 & 1.7 & 2.7 & 1.7 & 1.5 & 14.4 & $\mathrm{X}$ & $\mathrm{X}$ & -1.5 & 2.2 & 0.7 & 2.7 \\
\hline
\end{tabular}

TABLE 2: Comparisons between experimental and numerical thermal resistances of D.C. $30 \mathrm{~W}$.

\begin{tabular}{lccccc}
\hline & $R_{L}$ & $R_{M}$ & $R_{\mathrm{HS}}$ & $R_{a}$ & $R_{t}$ \\
\hline $\begin{array}{l}\text { Measured data } \\
\left({ }^{\circ} \mathrm{C} / \mathrm{W}\right)\end{array}$ & 0.33 & 0.47 & 0.03 & 0.47 & 1.30 \\
$\begin{array}{l}\text { Simulation result } \\
\left({ }^{\circ} \mathrm{C} / \mathrm{W}\right)\end{array}$ & 0.30 & 0.52 & 0.02 & 0.48 & 1.32 \\
Error $(\%)$ & 9.1 & -10.6 & 33.3 & -2.1 & -1.5 \\
\hline
\end{tabular}

flow may happen when Rayleigh number $(\mathrm{Ra})$ is larger than the value of $1.0 \times 10^{9}$. The ratio value of $\mathrm{Ra}$ to $\mathrm{Gr}$ is named by the Prandtl number $(\mathrm{Pr})$. We evaluate these dimensionless numbers that the maximum $\mathrm{Re}$ is about $1.0 \times 10^{3}$, the $\mathrm{Pr}$ is 0.71 , and the approximate $\mathrm{Ra}$ is $1.9 \times 10^{7}$ in the present study. Therefore, the approximate $\mathrm{Gr}$ is $2.7 \times 10^{7}$. The Richardson number (Ri) of "Gr/Re" is about 27 to verify the present study is free convection assumption. Consequently, with the exception of some simple cases, heat transfer relations in free convection are based on experimental studies.

Tables 1 and 2 show all experimental and simulation temperatures and thermal resistances at input power of D.C. $30 \mathrm{~W}$ incline angle of $0^{\circ}$. The errors are within $4 \%$ between experimental and simulation temperature except
$\mathrm{CH}$ 9. And their total thermal resistances are all $1.29 \mathrm{~W} / \mathrm{mk}$. The simulation results are in agreement with experimental results. The present CFD model is proper for simulating the LED lighting module. Tables 3 and 4 exhibit all experimental and simulation temperatures and thermal resistances at input power of A.C. $30 \mathrm{~W}$ incline angle of $0^{\circ}$. The errors are within $7 \%$ between experimental and simulation temperature except $\mathrm{CH}$. And their total thermal resistances are, respectively, $1.31 \mathrm{~W} / \mathrm{mk}$ and $1.26 \mathrm{~W} / \mathrm{mk}$. The differences between the calculated fin temperatures and the experimental data are slight based on Tables 1 and 3, which can verify the reliability and accuracy of the results obtained. Furthermore, as it can be observed from these tables, the accuracy of the present work in comparisons is good. All experimental temperatures with times are shown in Table 5 under three input powers, $16 \mathrm{~W}$, $20 \mathrm{~W}$, and $24 \mathrm{~W}$, and three incline angles. For D.C. $16 \mathrm{~W}$, they reach stability at almost 20 minutes. The maximum temperatures are $51^{\circ} \mathrm{C}$ for $0^{\circ}$ and $90^{\circ}$ and $52.3^{\circ} \mathrm{C}$ for $-90^{\circ}$. For D.C. $20 \mathrm{~W}$, they reach stability at almost 30 minutes. The maximum temperatures are $55^{\circ} \mathrm{C}$ for $0^{\circ}$ and $90^{\circ}$ and $56.1^{\circ} \mathrm{C}$ for $-90^{\circ}$. For D.C. $24 \mathrm{~W}$, they reach stability at almost 40 minutes. The maximum temperatures are $59^{\circ} \mathrm{C}$ for $0^{\circ}$ and $90^{\circ}$ and $60.3^{\circ} \mathrm{C}$ for $-90^{\circ}$. These temperatures of $-90^{\circ}$ are all higher than those of $0^{\circ}$ and $90^{\circ}$ resulting from these structures of fins, which impeded lifting flows at $-90^{\circ}$ inclination. And 
TABLE 3: Comparisons between experimental and numerical temperatures of A.C. $30 \mathrm{~W}\left(T_{a}=25.5^{\circ} \mathrm{C}\right)$.

\begin{tabular}{|c|c|c|c|c|c|c|c|c|c|c|c|c|c|c|c|}
\hline $\mathrm{CH}$ & 1 & 2 & 3 & 4 & 5 & 6 & 7 & 8 & 9 & 10 & 11 & 12 & 13 & 14 & 15 \\
\hline $\begin{array}{l}\text { Measured data } \\
\left({ }^{\circ} \mathrm{C}\right)\end{array}$ & 41.0 & 41.8 & 41.4 & 41.3 & 39.9 & 39.9 & 42.3 & 41.6 & 37.4 & 46.9 & 46.8 & 45.4 & 45.6 & 64.4 & 54.1 \\
\hline $\begin{array}{l}\text { Simulation result } \\
\left({ }^{\circ} \mathrm{C}\right)\end{array}$ & 39.9 & 39.8 & 40.0 & 40.6 & 38.7 & 39.3 & 39.3 & 39.9 & 44.8 & $\mathrm{X}$ & $\mathrm{X}$ & 44.2 & 42.9 & 62.6 & 53.8 \\
\hline Error (\%) & -2.6 & -4.7 & -3.3 & -1.6 & -3 & -1.5 & -7 & -4 & 14.4 & $\mathrm{X}$ & $\mathrm{X}$ & -2.6 & -5.9 & -2.4 & -0.5 \\
\hline
\end{tabular}

TABLE 4: Comparisons between experimental and numerical thermal resistances of A.C. $30 \mathrm{~W}$.

\begin{tabular}{lccccc}
\hline & $R_{L}$ & $R_{M}$ & $R_{\mathrm{HS}}$ & $R_{a}$ & $R_{t}$ \\
\hline $\begin{array}{l}\text { Measured data } \\
\left({ }^{\circ} \mathrm{C} / \mathrm{W}\right)\end{array}$ & 0.34 & 0.42 & 0.02 & 0.51 & 1.29 \\
$\begin{array}{l}\text { Simulation result } \\
\left({ }^{\circ} \mathrm{C} / \mathrm{W}\right)\end{array}$ & 0.29 & 0.46 & 0.03 & 0.46 & 1.24 \\
Error $(\%)$ & 14.7 & -9.5 & -33.3 & 9.8 & 3.9 \\
\hline
\end{tabular}

the thermal streams considered thus far had a principle body dimension aligned primarily with the direction of action of the gravity force [17]. The resultant flow patterns were parallel to its surface. For other inclinations, the principal body dimension is nearly perpendicular to the gravity vector and hence to the direction of action of the buoyance force especially for $90^{\circ}$ inclination.

Experimental study of the final goal is to improve and optimize the thermal module of fin section and lower LED junction temperature. The present original thermal module has the highest fin of $37 \mathrm{~mm}$. Thus, $37 \mathrm{~mm}$ fin height as a standard modifies the fin geometry and improves the required optimum fin pitch of $8.4 \mathrm{~mm}$ and the best fin thickness of $5.4 \mathrm{~mm}$, but the fear have error, so there is calculated in the optimal spacing of the thickness reduction with the addition of $1 \mathrm{~mm}$ as shown in Table 6 . Table 6 displays the modified fin computed from the original fin to optimize spacing and thickness. In summary, we select $(5.4 \pm 1,8.4 \pm 1)$ employed into numerical analysis in order to compare the thermal performances between them. Therefore, there are nine fin designs including $(4.4,7.4),(4.4,8.4),(4.4$, $9.4),(5.4,7.4),(5.4,8.4),(5.4,9.4),(6.4,7.4),(6.4,8.4)$, and $(6.4,9.4)$ to consider the optimum LED thermal module. The best result pitch is the $9.4 \mathrm{~mm}$ and the optimum thickness is the $4.4 \mathrm{~mm}$. The modified fin count is 14 . Figure 8 reveals that the modified thermal module with about $1.43 \mathrm{~kg}$ reduced the weight of $490 \mathrm{~g}$. The optimum pitch and thickness in order, first set the ambient temperature is $25^{\circ} \mathrm{C}$, will find that the original LED temperature drop of $2.9^{\circ} \mathrm{C}$, if the original AlMCPCB to heat spreader plate (Vapour Chamber, V.C.) [17], which fins did not improve when the LED temperature $59.1^{\circ} \mathrm{C}$, the temperature of the fin improved $55.2^{\circ} \mathrm{C}$, the temperature difference at $4.1^{\circ} \mathrm{C}$ as shown in Table 7 . The reason is that the interior working fluid of the V.C. does not burn out after the operating temperature scope, taking along the quantity of heat flow through the working fluid vaporization. This causes the V.C. to dissipate in a two-dimensional direction, making thermal spreading effect better than that of the Al-MCPCB.

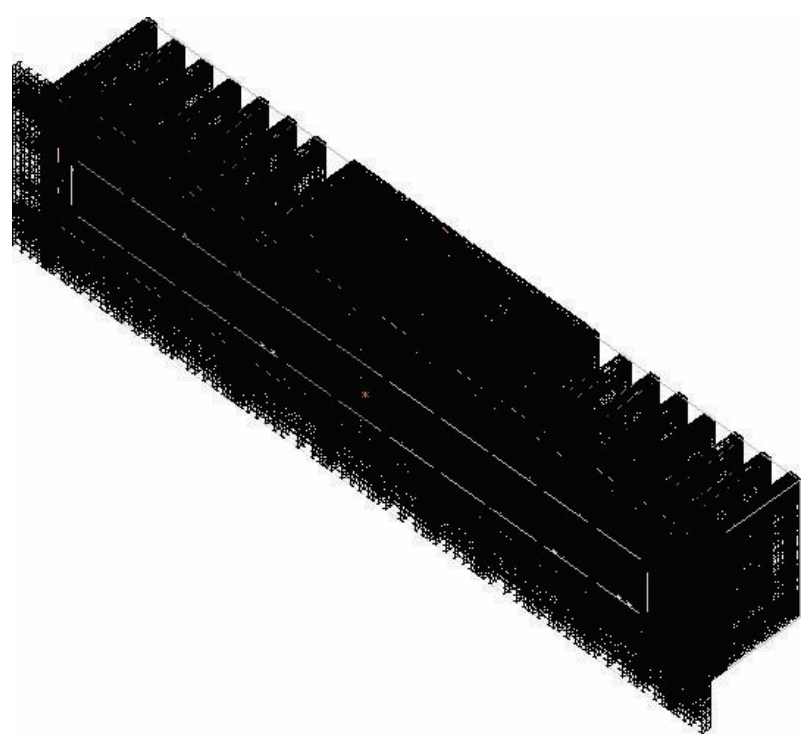

Figure 8: Modified fins.

Hence, the LED vapor chamber-based plate quickly dissipates the heat flow from LED heat sources to the exterior cooling module resulting from the interior two-phase flow.

\section{Conclusion}

For centuries, all mankind have applied light generated by thermal radiation on many lighting things; now rapid progress of semiconductor and solid-state cold light technologies in recent decades make mankind forward to green environmental protection and energy-saving lighting world in the 21st century. The present paper describes thermal performance experiments to investigate and design the HiLED lighting thermal module and achieve the optimization of the fin parameters under the natural convection. Results show that the thermal performance of the vapour chamber is better than that of Al-MCPCB, proving that it can effectively reduce the LED junction temperature. And comparing numerical results with the experimental values, the calculating error is no more than $\pm 7 \%$ based on some specified conditions in this study. The thermal performance of the Hi-LED lighting module with modified fins and V.C. is better than that of the original LED lighting module above $6.5^{\circ} \mathrm{C}$. We establish the relations between experimental and numerical studies in the present paper. The numerical results are in good agreement with the experimental results in the present study. 
TABLE 5: Experimental temperatures.

\begin{tabular}{|c|c|c|c|c|c|c|c|c|c|c|c|c|c|c|c|}
\hline $\begin{array}{l}\text { Time } \\
(\mathrm{min} .)\end{array}$ & $\mathrm{CH} 1$ & $\mathrm{CH} 2$ & $\mathrm{CH} 3$ & $\mathrm{CH} 4$ & $\mathrm{CH} 5$ & $\mathrm{CH} 6$ & $\mathrm{CH} 7$ & $\mathrm{CH} 8$ & $\mathrm{CH} 9$ & $\mathrm{CH} 10$ & $\mathrm{CH} 11$ & $\mathrm{CH} 12$ & $\mathrm{CH} 13$ & CH14 & $\mathrm{CH} 15$ \\
\hline \multicolumn{16}{|c|}{$16 \mathrm{~W} \_90^{\circ}\left(T_{a}=27.4^{\circ} \mathrm{C}\right)$} \\
\hline 0 & 27.4 & 27.3 & 27.3 & 27.4 & 27.3 & 27.4 & 27.4 & 27.4 & 27.4 & 27.4 & 27.3 & 27.4 & 27.4 & 27.4 & 27.4 \\
\hline 0.5 & 28.7 & 28.7 & 28.9 & 28.9 & 27.4 & 27.5 & 27.5 & 27.5 & 27.4 & 28.1 & 28.3 & 30.6 & 29.4 & 41.7 & 34.9 \\
\hline 1 & 29.9 & 30.1 & 30.6 & 31.1 & 27.6 & 28.1 & 28.2 & 28.1 & 27.9 & 29.9 & 30.1 & 33 & 31.8 & 46 & 37.9 \\
\hline 5 & 31.2 & 31.1 & 31 & 31.5 & 28.7 & 28.9 & 29 & 29 & 27.9 & 30.7 & 31.1 & 33.2 & 32.2 & 46.6 & 38.4 \\
\hline 10 & 32 & 32.3 & 32.3 & 33 & 29.8 & 30.1 & 30 & 30.2 & 28.8 & 32.4 & 32.7 & 34.3 & 33.6 & 47.4 & 39.2 \\
\hline 20 & 33.1 & 32.6 & 33.2 & 33.6 & 31.1 & 31.9 & 31.5 & 31.6 & 30.1 & 34.6 & 35 & 35.8 & 33.9 & 47.4 & 39 \\
\hline 30 & 34.7 & 34 & 34.8 & 35.3 & 32.2 & 32.8 & 33 & 33.4 & 31.3 & 36.1 & 36.6 & 37.5 & 36.2 & 48.5 & 40.2 \\
\hline 40 & 35.3 & 35.3 & 36.1 & 36.8 & 33.3 & 34 & 33.6 & 34.1 & 32.2 & 37.5 & 38 & 38.2 & 37.6 & 49.5 & 41.3 \\
\hline 50 & 35.5 & 36.7 & 36.1 & 37.3 & 34.3 & 35.1 & 34.6 & 35.1 & 33.2 & 38.7 & 39 & 39.4 & 37.9 & 50 & 41.9 \\
\hline 60 & 36.2 & 36.3 & 35.4 & 36.8 & 35.6 & 35.2 & 35.1 & 36.2 & 33.7 & 39.3 & 39.4 & 39.3 & 38.3 & 51.3 & 42.9 \\
\hline \multicolumn{16}{|c|}{$16 \mathrm{~W} \_0^{\circ}\left(T_{a}=28.5^{\circ} \mathrm{C}\right)$} \\
\hline 0 & 28.4 & 28.6 & 28.5 & 28.6 & 28.5 & 28.6 & 28.6 & 28.6 & 28.4 & 28.6 & 28.6 & 28.5 & 28.5 & 28.4 & 28.4 \\
\hline 0.5 & 29.7 & 29.7 & 30 & 30.1 & 28.7 & 29.1 & 29 & 29.2 & 28.4 & 30 & 30.4 & 32 & 30.6 & 43.5 & 36.6 \\
\hline 1 & 30.4 & 30.9 & 31.3 & 31.3 & 28.9 & 29.4 & 29.4 & 29.4 & 28.5 & 30.5 & 30.9 & 32.8 & 31.4 & 47.1 & 39.2 \\
\hline 2 & 30.5 & 30.6 & 31.2 & 31.5 & 29.1 & 29.9 & 29.7 & 29.8 & 28.7 & 30.9 & 31.5 & 33.2 & 31.5 & 46.4 & 38.6 \\
\hline 3 & 30.8 & 31.1 & 31.8 & 31.9 & 29.2 & 30.2 & 30.1 & 30.2 & 28.6 & 31.3 & 31.7 & 33.2 & 32 & 47.1 & 39 \\
\hline 5 & 31.3 & 31.6 & 32.4 & 32.3 & 30.1 & 30.9 & 30.7 & 30.7 & 28.9 & 32 & 32.5 & 33.8 & 32.2 & 48.2 & 40 \\
\hline 10 & 32.1 & 31.7 & 32.1 & 32.9 & 30.8 & 32 & 31.6 & 31.9 & 29.5 & 33.3 & 33.7 & 34.7 & 33.1 & 47.3 & 39 \\
\hline 20 & 33.5 & 33.7 & 33.8 & 34.1 & 32.6 & 33.9 & 33.6 & 33.8 & 30.9 & 35.1 & 35.6 & 35.7 & 34.2 & 48.7 & 40.7 \\
\hline 30 & 33.6 & 34.5 & 35 & 34.8 & 33.7 & 35 & 34.8 & 35.1 & 31.9 & 36.2 & 36.8 & 36.2 & 35 & 50.1 & 41.9 \\
\hline 40 & 34.7 & 34.6 & 35.1 & 36 & 34.2 & 35.8 & 35.3 & 35.6 & 32.1 & 37 & 37.5 & 36.7 & 35.9 & 47.9 & 40.4 \\
\hline 50 & 35 & 35.4 & 35.2 & 35.7 & 34.8 & 36.3 & 35.9 & 36.2 & 32.8 & 37.5 & 38.1 & 37.4 & 36.2 & 49.3 & 41.2 \\
\hline 60 & 34.6 & 35.8 & 35.9 & 36.2 & 34.8 & 36.5 & 36.1 & 36.4 & 32.6 & 37.9 & 38.4 & 37.2 & 36.4 & 51.3 & 42.7 \\
\hline \multicolumn{16}{|c|}{$16 \mathrm{~W}_{-}-90^{\circ}\left(T_{a}=28.3^{\circ} \mathrm{C}\right)$} \\
\hline 0 & 28.2 & 28.2 & 28.2 & 28.2 & 28.2 & 28.4 & 28.3 & 28.3 & 28.4 & 28.4 & 28.3 & 28.2 & 28.2 & 28.2 & 28.2 \\
\hline 0.5 & 30.1 & 30.1 & 30.3 & 30 & 28.3 & 28.5 & 28.4 & 28.4 & 28.6 & 29.5 & 29.9 & 32 & 30.6 & 46.4 & 39.1 \\
\hline 1 & 30.1 & 30.3 & 30.4 & 30.5 & 28.3 & 28.5 & 28.4 & 28.4 & 28.4 & 29.8 & 30 & 32.1 & 30.9 & 46 & 38.2 \\
\hline 2 & 30.5 & 30.4 & 30.7 & 30.8 & 28.4 & 28.7 & 28.6 & 28.6 & 28.6 & 30.4 & 30.6 & 32.7 & 31.3 & 46.5 & 39 \\
\hline 3 & 31.2 & 31 & 31.3 & 31.4 & 29.2 & 29.5 & 29.1 & 29.1 & 28.9 & 30.8 & 31.3 & 33.3 & 31.9 & 47.3 & 39.4 \\
\hline 5 & 32.2 & 31.9 & 31.9 & 32 & 29.5 & 29.9 & 29.3 & 29.6 & 29.2 & 31.5 & 32 & 34.1 & 32.4 & 48.1 & 40.5 \\
\hline 10 & 33.7 & 33.2 & 33.1 & 33.1 & 30.8 & 31.1 & 30.4 & 30.7 & 30.4 & 33.2 & 33.7 & 35.4 & 33.7 & 49.3 & 41.8 \\
\hline 20 & 34.5 & 34.4 & 34 & 34.4 & 31.5 & 32.4 & 31.6 & 31.9 & 32.7 & 35.5 & 35.7 & 37.4 & 34.9 & 50 & 41.7 \\
\hline 30 & 36.5 & 36 & 35.8 & 35.7 & 32.9 & 33.6 & 32.7 & 33.3 & 34 & 37.1 & 37.4 & 38.9 & 36.3 & 51.7 & 44 \\
\hline 40 & 37.7 & 36.8 & 36.3 & 36 & 33.4 & 34.6 & 33.5 & 33.7 & 35 & 38.2 & 38.1 & 39.9 & 36.5 & 52.1 & 44.3 \\
\hline 50 & 38.5 & 37.8 & 36.6 & 37 & 34.5 & 35.3 & 33.7 & 34.5 & 36.2 & 39.1 & 39.1 & 40.4 & 37.6 & 53.1 & 45.4 \\
\hline 60 & 39.3 & 38.5 & 38.1 & 38.1 & 34.8 & 35.6 & 34.4 & 35.3 & 36.5 & 39.7 & 40 & 41.3 & 38.5 & 53.7 & 46.5 \\
\hline \multicolumn{16}{|c|}{$20 \mathrm{~W} \_90^{\circ}\left(T_{a}=26.9^{\circ} \mathrm{C}\right)$} \\
\hline 0 & 26.9 & 27 & 27 & 27 & 26.8 & 26.8 & 26.8 & 26.8 & 26.8 & 27 & 27 & 27 & 27 & 26.9 & 26.8 \\
\hline 0.5 & 28.8 & 29 & 29.6 & 29.4 & 26.4 & 26.7 & 26.6 & 26.6 & 26.6 & 28.5 & 28.7 & 32.1 & 30.2 & 46.4 & 39.5 \\
\hline 1 & 29.4 & 29.5 & 30.2 & 30 & 26.7 & 26.9 & 26.8 & 26.7 & 26.8 & 29.1 & 29.5 & 32.3 & 30.9 & 48.1 & 40.5 \\
\hline 10 & 32.2 & 32.4 & 33.2 & 33 & 29.3 & 30.1 & 29.3 & 29.3 & 28.7 & 33.2 & 33.6 & 35.8 & 34.4 & 51.2 & 43.2 \\
\hline 20 & 34.4 & 35 & 34.8 & 34.7 & 30.5 & 32 & 31.6 & 31.8 & 30.5 & 36.1 & 36.7 & 38.1 & 35.6 & 53.6 & 45.7 \\
\hline 30 & 36.2 & 35.9 & 36.1 & 36.8 & 31 & 32.3 & 31.9 & 32.4 & 32 & 38 & 38.3 & 39.4 & 37.5 & 53.8 & 46.6 \\
\hline 40 & 36 & 36.6 & 37.1 & 37.6 & 31.3 & 32.9 & 32.8 & 32.4 & 32.5 & 39.2 & 39.3 & 39.6 & 38.8 & 54.8 & 47 \\
\hline 50 & 36.3 & 37.5 & 36.4 & 37.5 & 33.4 & 35.3 & 35.1 & 35.4 & 33.2 & 39.9 & 40.1 & 40.2 & 37.4 & 54.8 & 46.1 \\
\hline 60 & 37.5 & 37.8 & 38.4 & 38 & 33.3 & 34.4 & 33.5 & 33.2 & 33.3 & 40.4 & 40.6 & 41.1 & 39.5 & 54.9 & 47.2 \\
\hline
\end{tabular}


TABle 5: Continued.

\begin{tabular}{|c|c|c|c|c|c|c|c|c|c|c|c|c|c|c|c|}
\hline $\begin{array}{l}\text { Time } \\
\text { (min.) }\end{array}$ & $\mathrm{CH} 1$ & $\mathrm{CH} 2$ & $\mathrm{CH} 3$ & $\mathrm{CH} 4$ & $\mathrm{CH} 5$ & $\mathrm{CH} 6$ & $\mathrm{CH} 7$ & $\mathrm{CH} 8$ & $\mathrm{CH} 9$ & $\mathrm{CH} 10$ & CH11 & $\mathrm{CH} 12$ & $\mathrm{CH} 13$ & $\mathrm{CH} 14$ & $\mathrm{CH} 15$ \\
\hline \multicolumn{16}{|c|}{$20 \mathrm{~W} \_0^{\circ}\left(T_{a}=28.0^{\circ} \mathrm{C}\right)$} \\
\hline 0 & 28.1 & 28 & 28 & 28.1 & 28.1 & 28.1 & 28.1 & 28.1 & 27.9 & 28.1 & 28.1 & 28.1 & 28.1 & 28.1 & 28.1 \\
\hline 0.5 & 30.4 & 30.2 & 30.8 & 30.9 & 28.1 & 28.6 & 28.6 & 28.6 & 28 & 29.9 & 30.3 & 33 & 31.3 & 48.7 & 40 \\
\hline 1 & 30.8 & 30.7 & 31.7 & 31.5 & 28.2 & 28.9 & 28.8 & 28.8 & 28.2 & 30.3 & 30.9 & 33.6 & 31.8 & 50.7 & 41.4 \\
\hline 2 & 31.1 & 30.7 & 31.5 & 31.4 & 28.8 & 29.4 & 29.2 & 29.3 & 27.9 & 30.8 & 31.3 & 33.8 & 31.8 & 50.6 & 40.6 \\
\hline 3 & 31.4 & 31.3 & 32.5 & 32.3 & 29.3 & 30 & 29.9 & 29.9 & 28.1 & 31.4 & 31.8 & 34.1 & 32.3 & 50.8 & 41.4 \\
\hline 5 & 31.9 & 32.3 & 33.2 & 33 & 30 & 30.9 & 30.8 & 30.8 & 28.8 & 32.3 & 33.1 & 34.8 & 33.1 & 52.2 & 42.4 \\
\hline 10 & 33.1 & 33.1 & 34.2 & 33.9 & 31.1 & 32.2 & 31.5 & 32.3 & 29.7 & 34.2 & 34.6 & 36.2 & 34.2 & 52.3 & 42.8 \\
\hline 20 & 34.3 & 35.3 & 35.1 & 35.6 & 33.7 & 35.1 & 34.9 & 35 & 31.5 & 36.6 & 37.2 & 37.3 & 35.6 & 53.7 & 43.5 \\
\hline 30 & 35 & 35.9 & 36.5 & 37 & 34.8 & 36.5 & 36.5 & 36.5 & 32.6 & 38.3 & 38.8 & 38.2 & 36.8 & 55.2 & 45.1 \\
\hline 40 & 35.9 & 37 & 36.5 & 36.9 & 36.1 & 37.6 & 37.3 & 37.6 & 33.7 & 39.2 & 40 & 39 & 37.2 & 55.5 & 45.5 \\
\hline 50 & 35.9 & 36.7 & 37.1 & 38.2 & 36.2 & 38.1 & 37.8 & 38.2 & 33.9 & 39.9 & 40.5 & 39.3 & 38.1 & 54.9 & 46.7 \\
\hline 60 & 35.9 & 38.1 & 37.7 & 38.5 & 36.8 & 38.7 & 38.5 & 38.7 & 34.3 & 40.4 & 41.1 & 39.4 & 38.6 & 56.1 & 46.3 \\
\hline \multicolumn{16}{|c|}{$20 \mathrm{~W}_{-}-90^{\circ}\left(T_{a}=26.5^{\circ} \mathrm{C}\right)$} \\
\hline 0 & 26.4 & 26.5 & 26.5 & 26.6 & 26.5 & 26.6 & 26.5 & 26.6 & 27.4 & 27.4 & 27.4 & 26.6 & 26.6 & 26.5 & 26.5 \\
\hline 0.5 & 28.4 & 28.6 & 28.5 & 28.6 & 26.5 & 26.8 & 26.6 & 26.7 & 27.2 & 28.3 & 28.7 & 30.8 & 29.4 & 45.8 & 38.3 \\
\hline 1 & 29.4 & 29.5 & 29.5 & 29.6 & 26.7 & 27.1 & 26.8 & 26.9 & 27.3 & 28.9 & 29.5 & 31.9 & 30.3 & 48.1 & 39.7 \\
\hline 2 & 29.5 & 29.5 & 29.3 & 29.8 & 26.9 & 27.6 & 27.5 & 27.5 & 27.3 & 29.5 & 30.1 & 32.3 & 30.7 & 48.1 & 39.2 \\
\hline 3 & 29.9 & 30.2 & 29.9 & 30.3 & 27.2 & 27.7 & 27.5 & 27.6 & 27.5 & 30.1 & 30.5 & 33 & 31 & 49.5 & 40 \\
\hline 5 & 30.8 & 31 & 30.9 & 31 & 27.8 & 28.4 & 28.2 & 28.5 & 27.9 & 31.1 & 31.4 & 33.8 & 31.9 & 49.8 & 41 \\
\hline 10 & 32 & 32 & 31.5 & 32.3 & 28.8 & 29.5 & 29.1 & 29.2 & 29.9 & 33 & 33.6 & 35.6 & 32.9 & 50.8 & 41.7 \\
\hline 20 & 34.6 & 34.8 & 34.2 & 34.9 & 31.2 & 32.1 & 31.5 & 31.6 & 32.3 & 35.9 & 36.3 & 38.1 & 35.5 & 53.1 & 44.1 \\
\hline 30 & 34.6 & 35.3 & 34.8 & 35.1 & 31.1 & 32.3 & 31.8 & 31.8 & 33.9 & 37.6 & 37.6 & 38.9 & 35.6 & 53.6 & 44 \\
\hline 40 & 34.8 & 36.3 & 35.6 & 36.2 & 31.7 & 33.1 & 32.5 & 33.2 & 35 & 38.6 & 38.8 & 39.7 & 36.8 & 54.4 & 44.7 \\
\hline 50 & 36.4 & 37.2 & 36.2 & 36.9 & 31.9 & 33.7 & 33.1 & 33.8 & 35.8 & 39.4 & 39.5 & 40.7 & 37.3 & 55.1 & 45.3 \\
\hline 60 & 36.3 & 37.1 & 36.3 & 36.5 & 32.1 & 33.6 & 32.7 & 33 & 36.5 & 39.8 & 40 & 41.3 & 36.8 & 54.9 & 45.1 \\
\hline \multicolumn{16}{|c|}{$24 \mathrm{~W} \_90^{\circ}\left(T_{a}=26.5^{\circ} \mathrm{C}\right)$} \\
\hline 0 & 26.4 & 26.4 & 26.5 & 26.4 & 26.4 & 26.4 & 26.4 & 26.4 & 26.4 & 26.6 & 26.6 & 26.5 & 26.5 & 26.6 & 26.5 \\
\hline 0.5 & 31.6 & 31.6 & 31.8 & 31.8 & 29.1 & 29.4 & 29.2 & 29.2 & 29.2 & 31 & 31.3 & 34.7 & 32.8 & 52.6 & 41.5 \\
\hline 1 & 32.1 & 31.9 & 32.1 & 32.2 & 29.1 & 29.6 & 29.6 & 29.6 & 29.2 & 31.7 & 31.9 & 35.3 & 33.5 & 53.6 & 42.4 \\
\hline 10 & 35 & 36.1 & 36 & 36.5 & 32.4 & 33.3 & 33.1 & 33.6 & 31.5 & 36.6 & 37.2 & 39.1 & 37.4 & 55.3 & 45 \\
\hline 20 & 36.1 & 36.7 & 37.2 & 37.8 & 35.6 & 36.6 & 36.3 & 36.5 & 34 & 39.9 & 40.3 & 41.5 & 38.8 & 56.8 & 45.8 \\
\hline 30 & 38.6 & 37.8 & 38.3 & 38.5 & 35.5 & 36.7 & 36.7 & 37.8 & 36.1 & 42.1 & 42.7 & 43.6 & 40.8 & 56.4 & 46.3 \\
\hline 40 & 38.8 & 37.8 & 38.5 & 38.4 & 37.5 & 38.5 & 37.3 & 38.9 & 37.3 & 43.5 & 44 & 45.3 & 42.7 & 59.8 & 48.5 \\
\hline 50 & 38.9 & 38.8 & 39.3 & 38.5 & 37.2 & 38.7 & 38.1 & 39.7 & 38.3 & 44.6 & 45.2 & 45.3 & 42.1 & 59.2 & 50 \\
\hline 60 & 38.9 & 39.8 & 40.3 & 38.7 & 37.5 & 38.9 & 39.4 & 40.6 & 38.9 & 45.1 & 45.8 & 44.6 & 43.6 & 59.4 & 50.6 \\
\hline \multicolumn{16}{|c|}{$24 \mathrm{~W} \_0^{\circ}\left(T_{a}=28.4^{\circ} \mathrm{C}\right)$} \\
\hline 0 & 28.4 & 28.4 & 28.4 & 28.4 & 28.4 & 28.5 & 28.5 & 28.5 & 28.5 & 28.5 & 28.5 & 28.5 & 28.5 & 28.5 & 28.5 \\
\hline 0.5 & 30.6 & 30.5 & 31.1 & 30.9 & 28.4 & 28.6 & 28.6 & 28.5 & 28.3 & 29.8 & 30 & 34.1 & 31.8 & 52.6 & 43.1 \\
\hline 1 & 31.6 & 31.4 & 32.6 & 32.3 & 28.6 & 29 & 28.9 & 28.8 & 28.6 & 30.7 & 31.3 & 34.9 & 32.9 & 55.1 & 44.3 \\
\hline 2 & 31.9 & 31.7 & 32.7 & 32.6 & 28.9 & 29.5 & 29.2 & 29.3 & 28.3 & 31.4 & 31.8 & 35.6 & 33.2 & 55 & 43.7 \\
\hline 3 & 32.3 & 32.3 & 33.3 & 33.3 & 29.5 & 30.1 & 30 & 30 & 28.5 & 32 & 32.5 & 35.7 & 33.5 & 55.3 & 44.1 \\
\hline 5 & 32.9 & 32.6 & 33.9 & 33.7 & 30.1 & 30.9 & 30.9 & 30.8 & 28.8 & 32.7 & 33.2 & 36.4 & 34.2 & 56.2 & 45.2 \\
\hline 10 & 34.6 & 34.5 & 35.5 & 35.4 & 32.3 & 33.8 & 33.6 & 33.7 & 30.7 & 35.6 & 36.3 & 38.1 & 35.8 & 56.9 & 46.1 \\
\hline 20 & 36.7 & 36.7 & 37 & 38 & 35.6 & 37 & 36.5 & 36.7 & 32.6 & 38.9 & 39.6 & 40.3 & 38.7 & 59.3 & 48.5 \\
\hline 30 & 36.9 & 38.3 & 38.2 & 39 & 37.1 & 38.7 & 38.4 & 38.6 & 34 & 40.8 & 41.3 & 40.9 & 39.3 & 59.9 & 49.3 \\
\hline 40 & 37.2 & 39.2 & 39.3 & 40.2 & 38 & 39.9 & 39.4 & 39.7 & 34.8 & 41.8 & 42.4 & 41 & 40.4 & 60.1 & 47.9 \\
\hline
\end{tabular}


TABle 5: Continued.

\begin{tabular}{|c|c|c|c|c|c|c|c|c|c|c|c|c|c|c|c|}
\hline $\begin{array}{l}\text { Time } \\
\text { (min.) }\end{array}$ & $\mathrm{CH} 1$ & $\mathrm{CH} 2$ & $\mathrm{CH} 3$ & $\mathrm{CH} 4$ & $\mathrm{CH} 5$ & CH6 & $\mathrm{CH} 7$ & $\mathrm{CH} 8$ & $\mathrm{CH} 9$ & $\mathrm{CH} 10$ & CH11 & $\mathrm{CH} 12$ & $\mathrm{CH} 13$ & CH14 & CH15 \\
\hline 50 & 37.5 & 39.8 & 39.5 & 40.7 & 38.6 & 40.7 & 40.6 & 40.5 & 35.6 & 42.7 & 43.3 & 41.4 & 40.6 & 61.3 & 48.6 \\
\hline 60 & 37.9 & 39.2 & 38.9 & 40 & 38.7 & 40.9 & 40.1 & 40.7 & 35.8 & 43.1 & 44 & 41.9 & 41.3 & 59.7 & 50.5 \\
\hline \multicolumn{16}{|c|}{$24 \mathrm{~W}_{-}-90^{\circ}\left(T_{a}=28.2^{\circ} \mathrm{C}\right)$} \\
\hline 0 & 28.1 & 28.3 & 28.2 & 28.3 & 28.1 & 28.3 & 28.1 & 28.3 & 28.3 & 28.3 & 28.3 & 28.3 & 28.1 & 28.1 & 28.1 \\
\hline 0.5 & 30.6 & 31.1 & 30.8 & 30.7 & 28 & 28.5 & 27.9 & 28.4 & 28.7 & 30.7 & 31.1 & 33.5 & 31.3 & 52 & 43.1 \\
\hline 1 & 31.5 & 31.4 & 31.7 & 32 & 28.5 & 29.1 & 28.3 & 28.6 & 29 & 31.4 & 31.9 & 34.5 & 32.1 & 53.5 & 43.9 \\
\hline 2 & 31.5 & 31.8 & 31.8 & 32.2 & 28.5 & 29.1 & 28.4 & 28.3 & 28.8 & 32.1 & 32.6 & 34.5 & 32.2 & 52.4 & 42.4 \\
\hline 3 & 31.8 & 32.3 & 31.8 & 32.4 & 28.9 & 29.8 & 29.4 & 29.8 & 29 & 32.7 & 33.2 & 34.9 & 33.3 & 52.8 & 43.8 \\
\hline 5 & 33.2 & 33.4 & 32.9 & 33.7 & 29.5 & 30.8 & 29.6 & 29.8 & 29.7 & 33.8 & 34.1 & 36.9 & 33.7 & 55.2 & 45.3 \\
\hline 10 & 34.7 & 35 & 35.2 & 35.1 & 30.8 & 32.3 & 31.1 & 32.3 & 31.1 & 36 & 36.4 & 38.7 & 35.4 & 56.4 & 46.6 \\
\hline 20 & 36.8 & 37 & 36.2 & 37.2 & 32.3 & 34.4 & 32.3 & 33.2 & 34.4 & 39.1 & 39.6 & 41.1 & 37.1 & 57.6 & 47.5 \\
\hline 30 & 38.2 & 38.4 & 37.8 & 38.4 & 33.1 & 35 & 33.1 & 34.1 & 36.3 & 40.9 & 41.3 & 42.6 & 38.1 & 58.6 & 48.6 \\
\hline 40 & 39.3 & 39.6 & 39.4 & 39.7 & 33.7 & 36.1 & 34.2 & 35 & 36.9 & 42.2 & 42.4 & 44 & 39.2 & 59.5 & 50 \\
\hline 50 & 38.9 & 39.8 & 38.9 & 40.4 & 33.8 & 36.2 & 34.4 & 35.9 & 38.3 & 42.9 & 43.4 & 43.8 & 40.3 & 59.4 & 48.9 \\
\hline 60 & 39.7 & 40.5 & 39.8 & 40.3 & 34.2 & 36.8 & 34.6 & 36.6 & 37.9 & 43.4 & 43.8 & 44.8 & 40.2 & 60.3 & 50.8 \\
\hline
\end{tabular}

TABLE 6: Optimization fin geometry $(3 \times 3)$.

\begin{tabular}{|c|c|c|c|}
\hline \multirow{2}{*}{$\begin{array}{l}S \\
(\mathrm{~mm})\end{array}$} & \multicolumn{3}{|c|}{$t(\mathrm{~mm})$} \\
\hline & 4.4 & 5.4 & 6.4 \\
\hline 7.4 & $\begin{array}{c}N=7 \\
\text { LED temperature } \\
60^{\circ} \mathrm{C} \\
\end{array}$ & $\begin{array}{c}N=7 \\
\text { LED temperature } \\
59.8^{\circ} \mathrm{C} \\
\end{array}$ & $\begin{array}{c}N=7 \\
\text { LED temperature } \\
59.7^{\circ} \mathrm{C}\end{array}$ \\
\hline 8.4 & $\begin{array}{c}N=7 \\
\text { LED temperature } \\
59.45^{\circ} \mathrm{C}\end{array}$ & $\begin{array}{c}N=7 \\
\text { LED temperature } \\
59.2^{\circ} \mathrm{C}\end{array}$ & $\begin{array}{c}N=7 \\
\text { LED temperature } \\
59.8^{\circ} \mathrm{C}\end{array}$ \\
\hline 9.4 & $\begin{array}{c}\mathrm{N}=7 \\
\text { LED temperature } \\
59.1^{\circ} \mathrm{C}\end{array}$ & $\begin{array}{c}N=7 \\
\text { LED temperature } \\
59.4^{\circ} \mathrm{C}\end{array}$ & $\begin{array}{c}N=7 \\
\text { LED temperature } \\
60.4^{\circ} \mathrm{C}\end{array}$ \\
\hline
\end{tabular}

TABLE 7: Comparisons between original design and modified design.

\begin{tabular}{|c|c|c|c|c|c|c|c|c|c|c|c|}
\hline & \multicolumn{11}{|c|}{$\mathrm{CH}$} \\
\hline & 1 & 2 & 3 & 4 & 7 & 8 & 9 & 12 & 13 & 14 & 15 \\
\hline Original fins $\left({ }^{\circ} \mathrm{C}\right)$ & 39.2 & 38.2 & 38.2 & 39.1 & 37.9 & 37.9 & 43 & 42.2 & 42.2 & 61.7 & 53.2 \\
\hline Optimal fins $\left({ }^{\circ} \mathrm{C}\right)$ & 37.5 & 37.8 & 37.8 & 38.6 & 36.8 & 36.7 & 42.5 & 41.6 & 42.5 & 58.8 & 51.1 \\
\hline Original fins with V.C. $\left({ }^{\circ} \mathrm{C}\right)$ & 42.1 & 41.2 & 41.2 & 42.3 & 41 & 40.7 & 45.8 & 44.9 & 44.9 & 59.1 & 53.1 \\
\hline Optimal fins with V.C. $\left({ }^{\circ} \mathrm{C}\right)$ & 37.6 & 37.8 & 37.8 & 38.8 & 36.8 & 36.7 & 42.7 & 41.7 & 42.4 & 55.2 & 49.7 \\
\hline
\end{tabular}

\section{Nomenclature}
$A$ : Area, $\mathrm{m}^{2}$
$H$ : Height, $\mathrm{m}$
$L$ : Length, $\mathrm{m}$
R: Thermal resistance, ${ }^{\circ} \mathrm{C} / \mathrm{W}$
T: Temperature, ${ }^{\circ} \mathrm{C}$
$W$ : Width, $\mathrm{m}$
$g$ : Gravitational acceleration, $\mathrm{m} / \mathrm{s}^{2}$
$h$ : Heat transfer coefficient, $\mathrm{W} / \mathrm{m}^{2}{ }^{\circ} \mathrm{C}$
$k$ : Thermal conductivity, $\mathrm{W} / \mathrm{m}^{\circ} \mathrm{C}$
$t$ : Thickness, $\mathrm{m}$

$q_{\text {in }}:$ Heat transfer rate, $\mathrm{W}$

Gr: Grashof number, dimensionless

Pr: Prandtl number, dimensionless

Ra: Rayleigh number, dimensionless

Re: Reynolds number, dimensionless

Ri: Richardson number, dimensionless.

\section{Subscripts}

a: Ambient

fin: Fin

V.C.: Vapour chamber. 


\section{Conflict of Interests}

The author declares that there is no conflict of interests regarding the publication of this paper.

\section{Acknowledgments}

The author is particularly grateful to Macroblock, lnc., and ARC Solid-State Lighting Corporation, for providing research funding for this study as well as samples of LED lamps. And the author also would like to thank all colleagues and students who contributed to this study.

\section{References}

[1] G. B. Stringfellow and M. George Craford, High Brightness Light Emitting Diodes: Semiconductors and Semimetals, vol. 48, chapter 2, Academic Press, San Diego, Calif, USA, 1997.

[2] J. C. Wang, "Investigation on application of LED to energysaving lamp," Combustion Quarterly 4, vol. 18, no. 1, pp. 3-11, 2009.

[3] J. H. Choi and M. W. Shin, "Thermal investigation of LED lighting module," Microelectronics Reliability, vol. 52, no. 5, pp. 830-835, 2012.

[4] C.-J. Weng, "Advanced thermal enhancement and management of LED packages," International Communications in Heat and Mass Transfer, vol. 36, no. 3, pp. 245-248, 2009.

[5] J. C. Wang, "Thermal investigations on LED vapor chamberbased plates," International Communications in Heat and Mass Transfer, vol. 38, no. 9, pp. 1206-1212, 2011.

[6] A. Christensen and S. Graham, "Thermal effects in packaging high power light emitting diode arrays," Applied Thermal Engineering, vol. 29, no. 2-3, pp. 364-371, 2009.

[7] M. Ha and S. Graham, "Development of a thermal resistance model for chip-on-board packaging of high power LED arrays," Microelectronics Reliability, vol. 52, no. 5, pp. 836-844, 2012.

[8] J. C. Wang, "Thermoelectric transformation and illuminative performance analysis of a novel LED-MGVC device," International Communications in Heat and Mass Transfer, vol. 48, pp. 80-85, 2013.

[9] J. C. Wang and C. L. Huang, "Vapor chamber in high power LEDs," in Proceedings of the 5th International Microsystems, Packaging, Assembly and Circuits Technology Conference (IMPACT '10), pp. 1-4, Taipei, Taiwan, 2010.

[10] E. Eisermann, K. Höll, W. Smetana, W. Tusler, M. Unger, and J. Whitmarsh, "Comparison of low cost, insulated aluminium substrates used as integrated heat sinks with conventional technology," Microelectronics International, vol. 26, no. 2, pp. 39, 2009.

[11] M. Arik, J. Petroski, and S. Weaver, "Thermal challanges in the future generation solid state lighting applications: light emitting diodes," in Proceedings of the 8th Intersociety Conference on Thermal and Thermommechanical phenomena in Electronic Systems, pp. 113-120, San Diego, Calif, USA, June 2002.

[12] M. Arik, C. Becker, S. Weaver, and J. Petroski, “Thermal management of LEDs: package to system," in Proceedings of the 3 rd International Conference on Solid State Lighting, vol. 5187, pp. 64-75, August 2003.
[13] J. C. Wang, R. T. Wang, T. L. Chang, and D. S. Hwang, "Development of 30 Watt high-power LEDs vapor chamberbased plate," International Journal of Heat and Mass Transfer, vol. 53, no. 19-20, pp. 3990-4001, 2010.

[14] H. S. Huang, Y. C. Chiang, C. K. Huang, and S. L. Chen, "Experimental investigation of vapor chamber module applied to highpower light-emitting diodes," Experimental Heat Transfer, vol. 22, no. 1, pp. 26-38, 2009.

[15] J. C. Wang, "Thermal module design and analysis of a $230 \mathrm{~W}$ LED illumination lamp under three incline angles," Microelectronics Journal, vol. 45, no. 4, pp. 416-423, 2014.

[16] J. C. Hsieh, H. J. Huang, and S. C. Shen, "Experimental study of micro rectangular groove structure covered with multi mesh layers on performance of flat plate heat pipe for LED lighting module," Microelectronics Reliability, vol. 52, pp. 1071-1079, 2012.

[17] J. C. Wang and S. L. Chen, "Air cooling module applications to consumer-electronic products," InTech, chapter 14, pp. 339-366, 2011.

[18] J. C. Wang and R. T. Wang, "A novel formula for effective thermal conductivity of vapor chamber," Experimental Techniques, vol. 35, no. 5, pp. 35-40, 2011. 

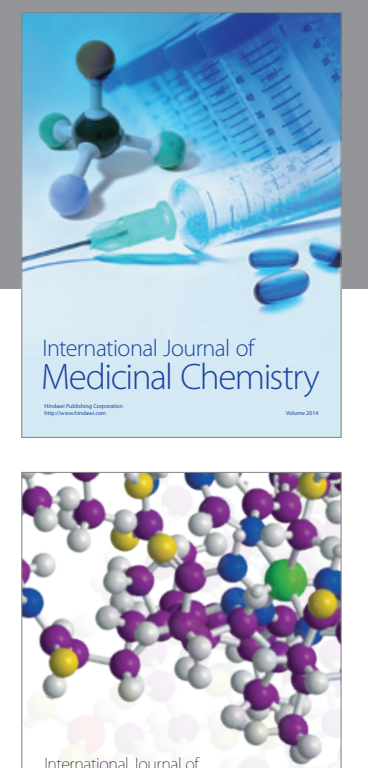

\section{Carbohydrate} Chemistry

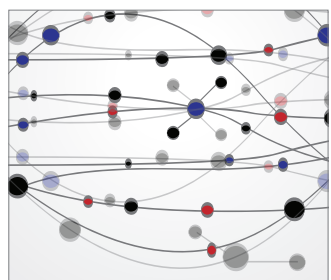

The Scientific World Journal
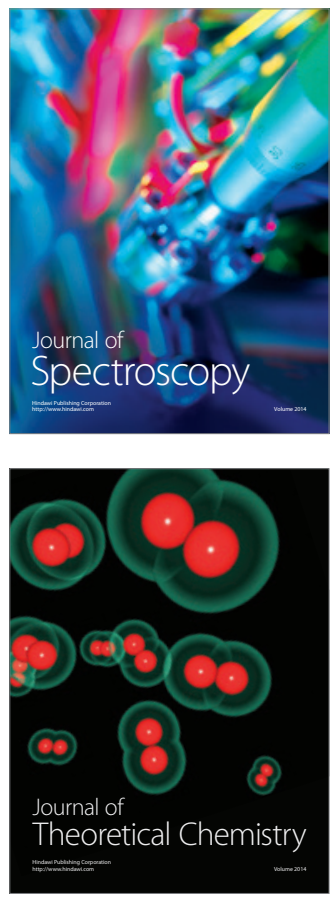
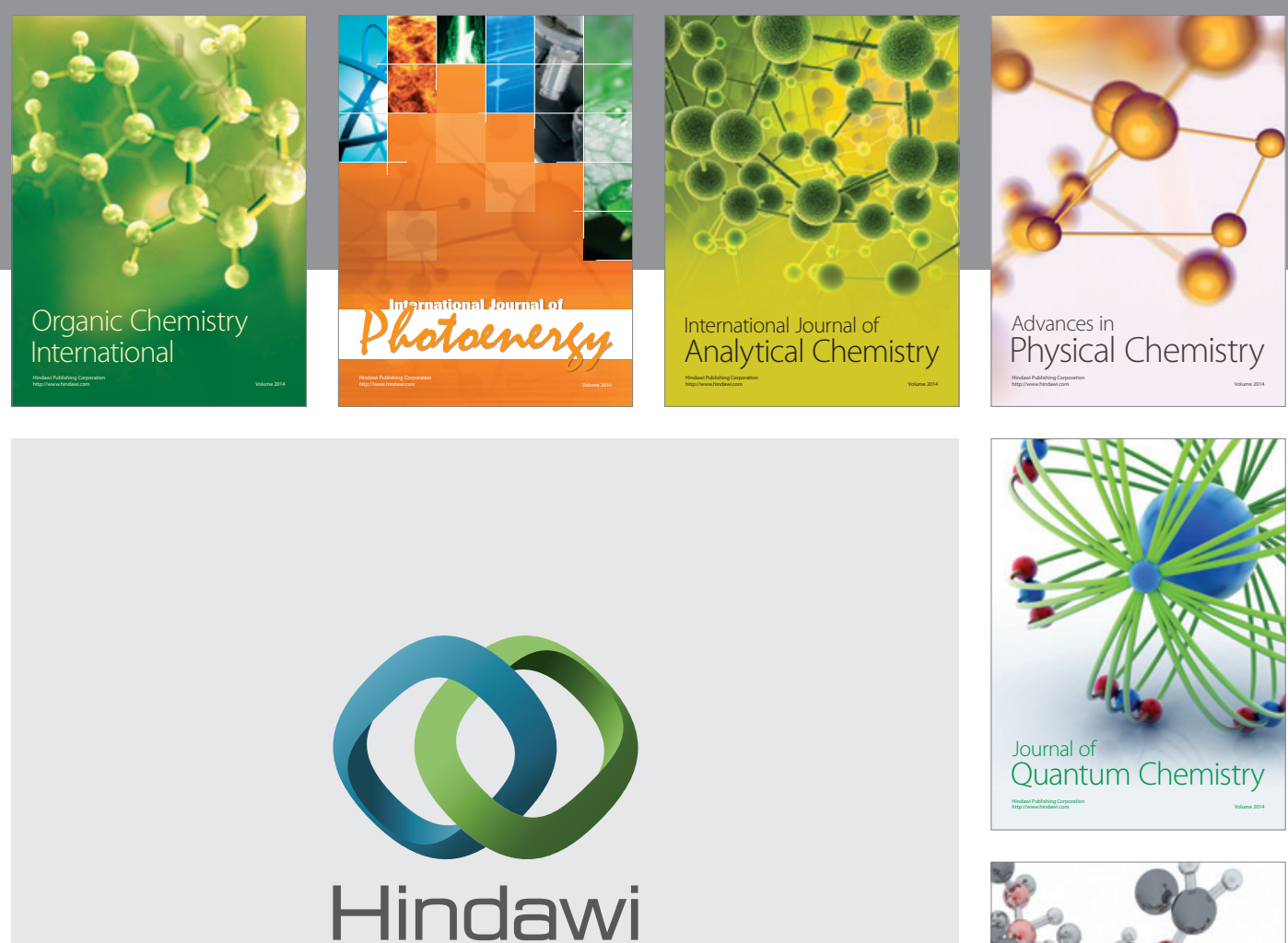

Submit your manuscripts at

http://www.hindawi.com

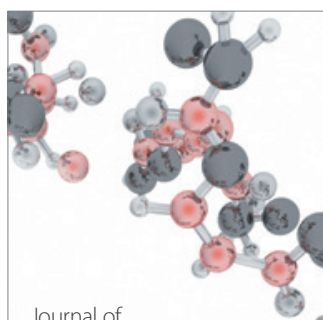

Analytical Methods

in Chemistry

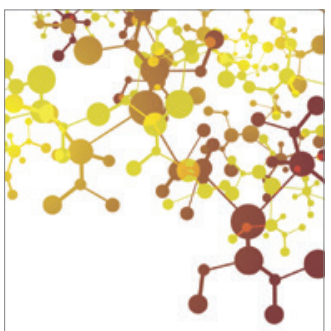

Journal of

Applied Chemistry

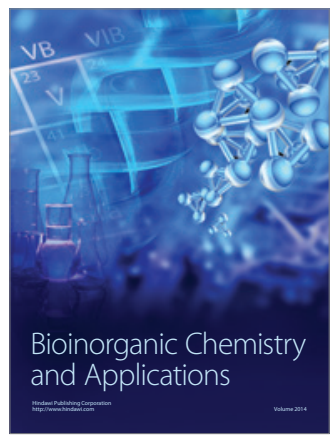

Inorganic Chemistry
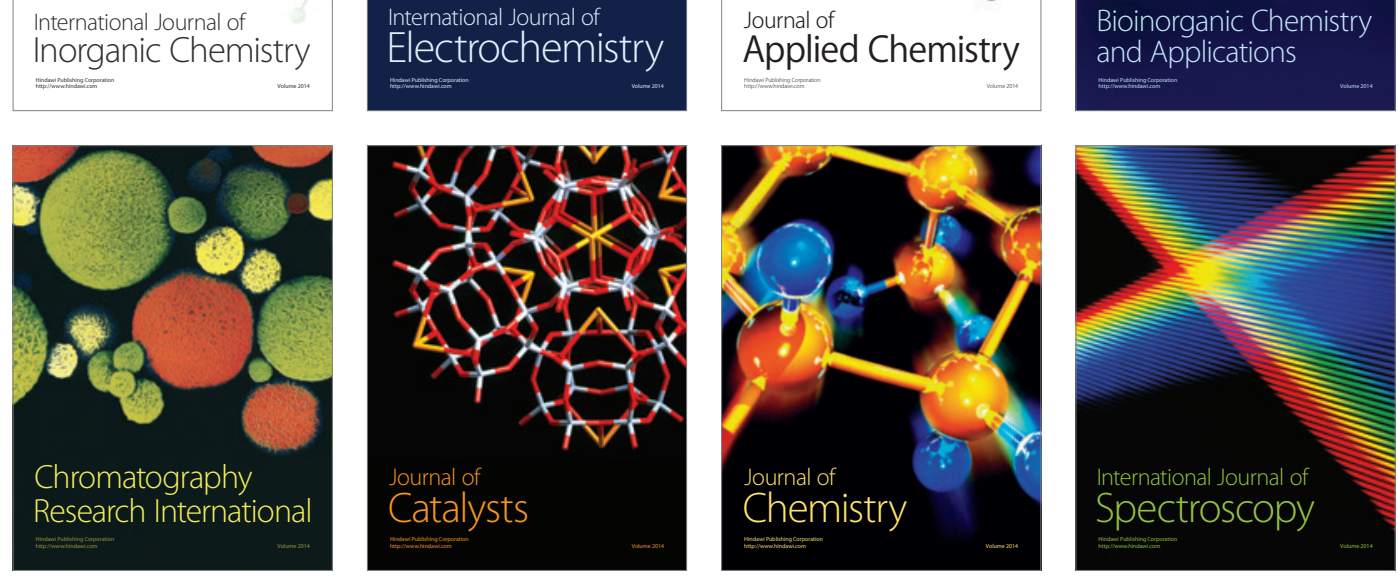